\title{
Walking in/as Publics: \\ Editors Introduction
}

Stephanie Springgay ${ }^{1}$ and Sarah E. Truman ${ }^{2}$

${ }^{1}$ University of Toronto, Toronto, Canada and ${ }^{2}$ University of Melbourne, Melbourne, Australia 


\section{Why Walking Now?}

Walking has an extensive history in the arts, humanities and social sciences as an artistic practice, as part of public programming and pedagogy in museums, schools and community spaces, and as a research methodology that is attentive to place, situated knowledges, sensory experiences and movement. More recently, there is a renewed interest in walking, as indicated by the number of organizations, publications, symposia, research projects, and artistic events that foreground walking. WalkingLab (www.walkinglab.org), a queer-feminist walking research-creation collective co-directed by Stephanie Springgay (University of Toronto) and Sarah E. Truman (University of Melbourne), has emerged as a leader in the area of walking studies. WalkingLab organizes international walking events, conducts research with diverse publics including youth in schools, and collaborates with artists and scholars to realize sitespecific research-creation events ${ }^{i}$ that complicate and rupture the White-cis-hetero-ableistpatriarchal canon of walking scholarship.

The sense of urgency and expediency surrounding walking is entangled with the desire to generate research and knowledge in situ, that is community-based, and that is attuned to more-than-human entanglements and encounters (Bates \& Rhys-Taylor, 2017; O’Neill \& Roberts, 2019; Springgay \& Truman, 2018). In an era of complex social and political issues - such as climate change, capitalism, and forced migration, to name a few-there is an increasing demand for public and community action. Further, academics continue to grapple with ways to present research findings to non-academic audiences, while marginalized and oppressed people take up ways to transform and decolonize social and political space and institutions. To this end, walking has become more than a utilitarian or pedestrian mode of getting from place to place; walking is an ethical and political call to collective action.

The renewed interest in the ethics and politics of walking is evident in the social sciences through a range of theoretical frameworks and methods, including the walking interview, which enables researchers to contextualize not only the lives of their research participants but also the places where they live, work and are social. Charlotte Bates and Alex Rhys-Taylor (2017) write: "By sharing conversations in place and at the participants' pace, researchers are beginning to more fully appreciate the transient, embodied and multisensual aspects of 'the social'" (p. 2). This attention to the corporeality of the walking interview is extended by Maggie O’Neill and Brian Roberts' (2019) 'walking interview biographical method' (see also O'Neill \& Einashe, this issue), which investigates participants' daily life experiences 'on the move.' Combining walking with biographical methods, researchers are able to think critically about daily mobility in relation to issues of migration and borders, and the increasing ways that people must move in order to survive.

Critical work on place studies has also had an impact on walking research. In particular, Eve Tuck and Marcia McKenzie's (2015) work, which brings together critical place inquiry with Indigenous research methods and worldviews, has argued for the need to contextualize participants' understandings of place alongside an examination of place itself "in its social and material manifestations" (p. 101). Critical place inquiry asks questions about the imbrications of place with globalization, settler colonialism, transatlantic slavery, and environmental degradation. The concept of 'emplacement' has historically been linked to walking and place-based research, mobilized through the work of Sarah Pink (2009/2015). Pink draws on the work of David Howes (2005) who notes that emplacement "suggests the sensuous interrelationship of body-mind-environment" (p. 7). Yet, Tuck and McKenzie (2015) contend that emplacement continues settler-colonial replacement of Indigenous peoples and land. As such, they argue for a "deeper consideration of the land itself and its nonhuman inhabitants 
and characteristics as they determine and manifest place" (p. 40) in critical place inquiry. Moving from an emplaced understanding of walking, towards reciprocity and relationships, requires what Sandra Styres (2019) conceptualizes, as an understanding of Land as more than a physical or geographic place. Land, Styres writes, from an Indigenous worldview is both "space (abstract) and place/land (concrete); it is also conceptual, experiential, relational, and embodied" (p. 27); as such, "Land is spiritual, emotional, and relational" (p. 27). Storying Land, Styres contends, is an important part of decolonization and reconciliation. Here, storying refers to Indigenous stories of place, but also the ways in which Indigenous and settler people move with/on Land. Walking is a form of storying and counter-storying that disrupts dominant narratives and representations of place. As White settler artists and scholars, our work through WalkingLab has sought to highlight the erasure or invisibility of Indigenous knowledges and methods in walking research and pedagogy.

Walking and land are deeply connected in Jon Johnson and Karyn Recollet's (2019) work with First Story, an Indigenous-led community-based organization that is focused on researching, keeping, and sharing stories and knowledges of ongoing Indigenous presence in Toronto. One of First Story Toronto's most popular initiatives has been its walking tours of Indigenous presence in places across the city. These tours constitute important opportunities for participants and guides to engage in respectful conversations around Indigenous histories, communities, places, perspectives and knowledges. Other walking and arts practices similarly shift from a focus on an individual lone walker to collective walking practices that countermap, counter-archive, and speculatively re-story a different future (see Johnson \& Recollet, this issue). In addition to First Story and WalkingLab, other art-research hybrids are emerging that interrogate and experiment at the intersections between creative practice and research. For example, the Museum of Walking (MoW), directed by Angela Ellsworth at Arizona State University, is concerned with the relations between people, land, action and site. MoW emphasizes group walking events that deepen an awareness of place through shared walking and togetherness.

Significantly, amidst the urgency and renewed interest in walking, is a shift in the ethical and political (in)tensions that are brought to bear on questions of who gets to walk where, how we walk, under whose terms, and what kind of publics we can make (Springgay \& Truman, 2017a). This special issue, dedicated to Walking inlas Publics - released as a mobile counterpart to the annual Public Pedagogies conference in Melbourne, Australia, takes these questions seriously with research that engages and complicates the various pedagogical and political dimensions that are at work in the construction of publics and commons. This issue is available online, opensource, and accessible to broad publics interested in critical approaches to walking scholarship and public pedagogy.

\section{Critical Walking Methods \& 'Walking-with'}

Against the backdrop of health and well-being that promotes walking as a free and accessible way to exercise, critical walking scholarship accounts for the ways that walking is imbricated in legacies of settler-colonial harm, white supremacy, and functions to police and regulate bodies (Springgay \& Truman, 2017b; 2019a; Truman \& Springgay, 2019). Alexis Shotwell (2016) names the tendency to consider health as an individual and moral obligation "healthism," where "individuals are held responsible for their bodies, and obesity, diabetes, cancer, and other chronic conditions are rendered as moral failings" (p. 29). While walking may lead to increased exercise and have the potential to reduce stress, or be a mode of transportation that is less environmentally harmful, healthism points to the ways that walking can be commodified, convey moral judgements, and exclude particular bodies from access and mobility. 
In addition to the fraught ways in which walking and healthism are co-imbricated, walking is encumbered by the figure of the flâneur. The flâneur, we contend, is a problematic walking trope in that he is conditioned by autonomy, ability, Whiteness and masculinity, and as such he is able to walk anywhere, detached from the immediate surroundings (see Chandler et. al., this issue; Heddon \& Myers, this issue). In order to counter this overused figure, we frame our research as critical walking methodologies that don't assume walking is a convivial, automatically embodied, inclusive and depoliticized mode of doing research and teaching (Springgay \& Truman, 2019b; 2019c). Theoretically aligned with feminist theories, critical race theory, queer and trans theories, critical disability studies, affect studies, and anticolonialisms, we argue that walking methods must engage with the intersections of gender, race, sexuality and disability. Critical walking methodologies attend to walking beyond health or as an innovative method, and in particular take up walking with an attention to antiableism, anti-racism, and anti-colonialism. Critical walking methodologies insist that intersectionality, the place where research takes place, and how one moves through space be critically complicated and accounted for.

Intersectionality has become a term used to describe and analyze intersecting identities. However, as Jennifer Nash (2019) argues, the term must recognize its interdependent histories in black feminist scholarship, so as not to be "emptied of specific meaning" (p. 2). When intersectionality, Nash contends, is mobilized in the name of diversity and inclusion then intersectionality upholds existing structures rather than unsettling or undoing them. Intersectionality, Nash writes, citing Vivian May, becomes "ripe for extraction or expropriation" (as cited in Nash, 2019, p. 25). As editors, we recognize the ways that intersectionality is often oversimplified with a long list of identity markers, or what Lisa Loutzenheiser (2010) calls an "add and stir" effect. Bringing intersectionality to bear on walking studies demands "unravelling the complexities of identities themselves" (Loutzenheiser \& Erevelles, 2019, p. 381 ), and consequently the ways that walking materializes and manifests multiple, affective, and entangled identities.

At WalkingLab, we approach critical walking methodologies as a practice of 'walkingwith,' informed by queer, feminist, Black, Indigenous, and People of Colour scholarship, and frictional engagements with theories such as the new materialisms, posthumanisms, and the inhuman. Our practice of walking-with is informed by Indigenous scholars Juanita Sundberg (2014), Bonnie Freeman (2015) and Jon Johnson (2015), who articulate with as a 'morethan' orientation. Withness is not simply about group walking practices, but rather emphasizes complicated relations and entanglements with humans, non-humans, Land, and an ethics of situatedness, solidarity and resistance. Walking-with is a deliberate strategy of unlearning, unsettling and queering how walking methods are framed and used in the social sciences and arts.

Although many of the articles in this special issue responded to our call to think and practice critical walking methodologies, we also recognize that most remain situated in Western frameworks. Our aim is that this special issue will encourage more scholarship on critical walking methodologies to flourish.

\section{Publics}

The field of public pedagogy considers the sites and instances of pedagogy that can occur outside of formal schooling, including the educational, cultural and social affects and effects of prevailing culture. Jennifer Sandlin, Jake Burdick and Michael O'Malley (2011) use the term critical public pedagogy to describe the ways popular and everyday culture(s) can be 
used to "... decode and interrupt dominant ideologies of race, class, gender, sexuality, militarism, and neo-liberalism" (p. 347). The papers in this journal are embedded in critical approaches to walking scholarship and pedagogy. In conversation with critical approaches to public pedagogy, our ongoing work with affect theory, and feminist new materialisms, we conceptualize the notion of 'publics' as not only formed between humans. Rather, 'publics' can refer to different kinds of commons and relations between humans and non-humans, ideas, and land. Some of these publics are linked to larger public(s) discourses, while others are activated as fugitive spaces or what might be considered an 'undercommons' (Harney \& Moten, 2013). Harney \& Moten's undercommons refers to a counter publics inhabited by Black, Indigenous, People of Colour, and disabled and d/Deaf people, who refuse to ask for recognition from a broken system, but rather "take apart, dismantle, tear down the structure that, right now, limits our ability to find each other, to see beyond it and to access the places that we know lie outside its walls" (Halberstam, 2013, p. 6). Kathryn Yusoff (2018), drawing on the work of Denise Ferreira da Silva, offers geo-Poethics as a Black feminist praxis that would 'end the world as we know it.' Yusoff (2018) writes: "Such an Anthropocene geoPoethics would turn against Man and the homogenizing impulse of humanist tropes into and another world of matter that puts race as central to the geosocial and geo-Poethical formations of the Anthropocene" (p. 104). What Yusoff and others are arguing for is not a better future based on inclusivity and diversity, but rather that the way forward will be by creating publics, spaces of collective defamiliarization that will radically tear apart and alter the world.

Publics need also encompass affects, emotions, and feelings that get constructed in a range of ways. Kathleen Stewart's (2007) work on the surfaces and textures of everyday life, and Ann Cvetkovich's (2012) writing about public feelings that attend to emotional registers of social and political relations, are necessary for thinking-feeling Walking in/as Publics. So too we might think about collaborative writing and scholarship as publics: a kind of receptivity to become more-than through the writing process (Springgay \& Truman, 2018).

As a pedestrian way of moving through space, walking is often overlooked as mundane or regarded as an activity mobilized for leisure, adventure, or discovery. In an era of global climate crisis and war, many migrating people are forced to walk out of fear for their lives, not for pleasure or innovation, while other people walk in order to perform daily labour such as carrying water or other commodities. We highlight these aspects of walking to embed our discussions of walking as a research methodology in a milieu that understands both the pedestrian and political entanglement of this everyday activity.

Each of the essays in this journal describes the co-creation of counter publics, minor publics, intimate publics, and different-kinds-of-undercommons through walking on five different continents (Africa, Asia, Australia, Europe, and North America). The various essays in this special issue complicate, interrogate and co-create different kinds of publics and commons that can be created through walking in conversation with theories and scholarship from critical race, disability, queer and trans, affect, inhuman, environmental humanities and more-than-human, and pedagogy.

As an emerging public and different kind of common, this special issue prioritizes voices from people who have positions outside of academia, including cultural workers and artists, graduate students, and early career researchers, as well as established scholars that utilize walking as a method, and educators who draw on public pedagogy in their scholarship. The journal is open access and speaks to a 'public' beyond the academic paywall. The issue came out of an open call, and includes different formats including long and short form essays and visual essays. 


\section{A Critical Syllabus for Walking in/as Publics: Curated as a Mobile Compliment to the Annual Public Pedagogies Conference}

Launched at the annual Public Pedagogies Conference in Melbourne, Australia in November, 2019 this special issue functions as an online, accessible, mobile element of the conference's theme. The twenty-five contributions that co-compose this special issue take up walking in various forms. It wasn't until we realized that we had curated twenty-five (way more than we'd originally planned!) essays of varying lengths, including visual essays, that we needed some kind of organizing principle. Rather than thinking about what each essay shared in common with each other in order to be grouped together, we imagined a format where the questions posed to each contribution was: what is 'at work' in the essay?; what is the thinking-making-doing of the piece?; or, how is the pedagogical force operating? Imagining our readers as constituting a public space of 'study' (Harney \& Moten, 2013), or what WalkingLab practices as an Itinerant Reading Salon, the contributions in this special issue are organized through five nodes - a syllabus in the making: walking and place; unlearning the flâneur; walking and the Anthropocene; spatial politics and counter-mapping; and interrogating publics and pedagogies beyond the classroom.

The first set of contributions tune into the different ways that walking and place-making are enmeshed. Margaret Somerville, writing with Leanne Tobin and Jacinta Tobin, considers how we can come to know the Nepean River Trail through walking the contemporary songlines of Darug songwriters and artists that sing the country of the riverlands today. The essay explores Somerville's walking practice, alongside a public performance of art and spoken word at the Circular Quay International Passenger Terminal in Sydney, Australia, to question a historic site of colonial invasion that is also the place of arrival for immigrants. The next piece is a poem by Wiradjuri writer Jeanine Leane drawn from her recent book Walk Back Over. The imperative to 'walk back over,' a line in the poem Whitefellas (in this issue), operates both literally and figuratively: referring to the need to revisit the past to see what has been missed, and pointedly, for white settlers to critically interrogate gestures of reconciliation on Aboriginal lands, and with Aboriginal peoples. The next piece takes place in London, UK where Margaret O’Neill and Ismail Einashe take up local places, such as shops, community centres, spas, hotels and schools, through walking as a biographical interview method (WIBM) in order to practice critical public pedagogy that engages in unsettling and troubling the white male privilege and basis of walking. The authors build upon a long history of doing social research using walking, participatory and arts-based methods on migration with migrants; and the importance of creating space for stories of asylum, migration and marginalization. The haunting images from Cathlin Goulding's photo essay examine places of exception that take form in prisons, jails, concentration camps, immigration detention centers, Indigenous boarding schools, suspension rooms in schools, and the refugee camp. Walking the former Tule Lake Japanese prison camp in Northern California, Goulding knots herself into the prisoners' restless and persistent presence and her own family history. Robert Bean and Barbara Lounder's essay and images contextualize their collaborative art project, Breathing-in-the-Breathable: An annotated walk, which took place among the ruins of a $19^{\text {th }}$-century tuberculosis sanatorium in the Polish town of Sokołowsko. The participatory walking project utilized an event score, objects, sound and embodied movement to explore how the atmosphere and environment became explicit and weaponized by the use of gas warfare during the First and Second World Wars. Blister is a verbatim play that tells the story of Rosie, an Australian woman who walks the Camino de Santiago, an $800 \mathrm{~km}$ pilgrimage across Northern Spain. Sarah Peters' essay describes how walking methods merged with the situated, relational 
and material verbatim theatre practice of community immersion in order to experience and represent the public pedagogy of the Camino in performance.

Our next syllabus entry is a series of compositions that critique the ableist, masculinist and heteronormative ways that walking has historically been inscribed in research. Eliza Chandler, Megan Johnson, Becky Gold, Carla Rice and Alex Bulmer take up works by disability artists, whose practices engage with the act of walking/traversing as a method and form of sense-making. 'Cripping the flâneur,' they ask how we might come to know ourselves, our cities, our neighbours, and blindness through the epistemological vantage-point of blindness. David Ben Shannon's essay provides a critical analysis of soundwalks through four methods: soundwalks, listening walks, phonographic walks, and audio walks, using exemplifications from his doctoral research project in an early childhood classroom, to suggest that a compositional attention to voice, music and inaudibility might make audible those populations whose oppression is enacted through their very inaudibility. Some of the earliest and most pivotal contributions by feminist scholars to walking is the work of Dee Heddon and Misha Myers, and in particular their work in dismantling the over-used trope of the flâneur. Their photo essay describes their Walking Library for Women Walking project, which explores the multiple relationships between walking, literature and environment. The Walking Library strategically intervenes into a walking art discourse in which women remain largely invisible. Georgina Perryman narrates her experience of participating in the Queer History Walking Tour, an annually recurring event during Dublin's official Pride festivities. As an activist form of public pedagogy, the walking tour encourages a relational understanding of queer cultural heritage through mobile, embodied and emotional interactions. Perryman argues that the walking tour works as an 'anarchive' that contributes to a growing, intersectional understanding of LGBTQ+ experiences and queer futures, facilitated by peripatetic practices.

The catastrophic consequences of climate change, toxic waste and water, extractive industries and capitalism theoretically inform the settings of the next section of walking methodologies. Astrida Neimanis and Perdita Phillips explicate a walkshop in a park dedicated to former coal-based infrastructures. The walkshop aimed to better understand the tensions around groundwater and extraction in Australia. The essay and accompanying images grapple with the attempt to engage bodily with groundwater, which for the most part is inaccessible to human experience. To do so they draw on the practice of posthuman phenomenology to explain how bodily attunement to wateriness, alongside the 'proxy stories' of arts and sciences expertise, can aid in bringing groundwater into lived experience. Randy Lee Cutler's visual essay details an ongoing performative walking project, SaltWalks, which takes participants on site-specific salt-tasting walks through different city neighborhoods. Through an engagement with this elemental mineral, these walks become a pedagogical platform that embodies aesthetic and philosophical enquiries into the importance of this substance to ritual, survival, health, industry and the imagination. As the many permutations of salt's diverse implications unfold, participants explore this crystalized mineral for its omnipresence in daily life, from modern plastics, cleaning agents, ceramics and leather, to cosmetics and pharmaceuticals. Another walkshop method is analyzed in Susanne Pratt and Kate Johnston's essay; Speculative Harbouring reflects on a postgraduate workshop in which students from different disciplines came together over an intent to care for, and with, urban harbours. Drawing on feminist practices and politics of care, in particular Maria Puig de la Bellacasa's articulation of 'matters of care,' alongside Anna Tsing's 'arts of noticing', the authors examine the ways in which walking and reflecting can attune people to learn to care. Karen Malone's essay concerns walking on blasted landscapes with children in Semipalatinsk, a city on the outskirts of the Polygon nuclear test site, on the 'Steppes' in eastern Kazakhstan. Through writing with with 
the past, she steps into an entangled set of uneasy encounters, remembering walking-with those who are deemed unworthy of recognition and are invisible in the obscene manifestations of capitalism, the arms race, and the cold war. In a visual essay, Mindy Blaise, Tonya Rooney and Jo Pollitt discuss their ongoing 'wanderings' with young children, problematizing the dominant discourse of developmentally appropriate practices that regulate children's bodies and their environments. Their weather wanderings rupture and intervene into the stronghold that child development and 'discovery' has on the field of early childhood education. Weather wanderings insist that children are always on the move with-weather.

The fourth section of our syllabus is concerned with matters of spatial politics and counter-mapping. Many of these essays could have been framed under walking and place, but there is always the challenge of assigning more than five readings per class! Swati Arora analyses the walking practice of Delhi-based artist Mallika Taneja, in the context of its engagement with, and intervention in, the contemporary conversations on sexualised violence, gender, space and mobility in India. Taneja's work is part of a variety of feminist activism to take place in India since the horrific gang rape of Jyoti Singh in Delhi in December 2012. Taneja organises regular midnight walks in various parts of the city. Arora examines the contours of embodied knowledge enabled by collective walking by women at midnight. She discusses how walking can allow for a learning process that is lived, somatic and personal, and which is rooted in specific spatial contexts based on listening and care. Jon Johnson and Karyn Recollet draw on their work with First Story, an Indigenous-led community-based organization that prioritizes stories and knowledges of ancient, ongoing, and future Indigenous presence in Tkaronto (Toronto). Their paper, and the walks they organize for First Story challenge the voyeurism of white privilege's entitlement to Indigenous lands, bodies, experiences, and knowledges. Johnson and Recollet draw on Indigenous futurisms and speculative fiction to activate slipstream cartographies and choreographies as part of their land based storytelling practices. Considering a precarious public pedagogy, Kimberly Powell's essay returns us to the historic and ethnic neighborhood of San Jose Japantown, California and her StoryWalks method. As a counter-mapping practice, StoryWalks gathers narratives from residents living in San Jose to underscore the entanglement of US social and economic infrastructures, discriminatory practices of spatialized place politics, and local narratives situated in place politics. Nazli Tümerdem's essay focuses on counter-mapping and walking in the precarious geographies of Northern Istanbul as experiential and place-based (un)learning, to produce multiple epistemologies, and generate a community that is critically engaged with top-down approaches to urbanization. Walis Johnson's visual essay explicates the practice of redlining in the United States, and her artistic research, The Red Line Archive Project and the Red Line Labyrinth, which archives and counter-maps this ongoing practice of geographies of race. Red Line Maps were used to exclude People of Colour, usually Black people, from the greatest source of wealth creation in America-homeownership. This insidious policy played out over time, impeding Black homeownership, wealth accumulation, and full participation in the US economy and political system. Yet, traces of redlining are evident today in myriad forms of economic and housing discrimination, inequitable education, policing, and poverty. Johnson's various walking projects expose the trauma and violence of redlining in New York. In her arts-based intervention into mapping and walking, Linda Knight outlines Inefficient Mapping in the next visual essay. Inefficient Mappings are gestural markings that take place in situ. The mapping is produced while walking and moving. It is possible to engage technologies such as tablet-based drawing apps. Alternatively, the mapping can be done using paper and conventional drawing tools. In each instance, the mappings record affective relations and movements. 
The final section of our critical walking syllabus brings educational researchers who use walking to inform their thinking about pedagogy, collaborative writing, and pedagogical exercises, and who invite students to move into publics beyond the confines of the classroom. While David Ben Shannon and Susanne Pratt and Kate Johnston (above) also discuss walking with students, they were curated into a different section, but should be read alongside these essays. Walking has always been mobilized in schools but is generally instrumentalized as a way of moving student bodies or framed through discovery. Scholars in this section think-with walking and pedagogy in different settings. Asilia Franklin-Phipps and Tristan Gleason interrogate the limitations of reflection in teacher education practitioner research that is solitary, ahistorical, and written in a particular academic register with an audience of one in mind. Their essay explores walking with a group of pre-service educators and argue that walking as reflective praxis produces different possibilities in the space of teacher education, which challenge the treatment of teaching and learning as ahistorical and universal. Nike Romano, Veronica Mitchell, and Vivienne Bozalek describe a walking-writing group practice as academics and educators in South African higher education. Following Haraway's (2016) 'staying with the trouble', and Tsing, Swanson, Gan and Bubandt's (2017) 'how to live on a damaged planet', the authors walked Rondebosch Common, a public space and national heritage site, in order to grapple with the complexities and ambivalences of finding common ground in a country devastated by colonial and apartheid violence. Wesam M. Salem, Leslee Bailey-Tarbett and Susan Naomi Nordstrom describe walks taken in a university course in Memphis, United States outside the confinement of the physical classroom into public spaces. By blurring boundaries and crossing limits, the authors displaced where and how teaching and learning materialized.

We are inspired by the variety of contributors to this issue and the nuance and depth that they take to thinking about walking and publics. In an era where academic publishing is being squeezed into regulated echo-chambers of journals owned by multi-national corporations and locked behind paywalls that some universities can't even afford, let alone individuals, it felt necessary to publish these conversations around walking in/with diverse publics on an opensource platform. We'd like to thank Karen Charman and Mary Dixon from the Public Pedagogy Institute for inviting WalkingLab to guest edit this issue. Special thanks to all the contributors for taking the time to attend to revisions, edits, and our ongoing queries, and for those who proposed articles that we couldn't quite fit in. Particular thanks to Associate Editor, David Ben Shannon for taking a major role in substantive editing; to managing editors James Miles and Anise Truman; designer Claire Rafferty; our anonymous copy-editor; and to all the peer reviewers whose labour shapes another publics that is fundamental to writing and learning. Stephanie would like to acknowledge the Social Sciences and Humanities Research Council (SSHRC) Institutional Grant for funding the copy-editing of this special issue. 


\section{References}

Bates, C., \& Rhys-Taylor, A. (Eds.). (2017). Walking through social research. London, UK: Routledge.

Cvetkovich, A. (2012). Depression: A public feeling. Durham, NC: Duke University Press.

Freeman, B. M. (2015). The spirit of Haudenosaunee youth: The transformation of identity and well-being through culture-based activism (Unpublished doctoral dissertation). Wilfrid Laurier University, Waterloo, Canada.

Halberstam, J. (2013). The wild beyond: With and for the undercommons. Forward to S. Harney and F. Moten, The undercommons: Fugitive planning \& black study (pp. 5-12). New York, NY: Minor Compositions.

Haraway, D. (2016). Staying with the trouble: Making kin in the Chthulucene. Durham, NC: Duke University Press.

Harney, S., \& Moten, F. (2013). The undercommons: Fugitive planning \& black study. New York, NY: Minor Compositions.

Howes, B. (2005). Empire of the senses: The sensual culture reader. New York: Berg.

Johnson, J. (2015). Pathways to the Eighth Fire: Indigenous knowledge and storytelling in Toronto (Unpublished doctoral dissertation). York University, Toronto, Canada.

Johnson, J., \& Recollet, K. (2019). Why Do You Need to Know That? Paper presented at the American Education Research Association annual conference, Toronto Canada.

Loutzenheiser, L. W. (2010). Can we learn queerly? Normativity and social justice pedagogies. In T. K. Chapman \& N. Hobbel (Eds.), The practice of freedom: Social justice pedagogy in the United States (pp. 121-143). New York, NY: Routledge.

Loutzenheiser, L. W., \& Erevelles, N. (2019). 'What's disability got to do with it?': Crippin' educational studies at the intersections. Educational Studies, 55(4), 375-386. https://doi.org/10.1080/00131946.2019.1630131

Nash, J. (2019). Black feminism reimagined after intersectionality. Durham, NC: Duke University Press.

O’Neill, M., \& Roberts, B. (2019). Walking methods: Research on the move. London, UK: Routledge.

Pink, S. (2015). Doing sensory ethnography. London, UK: Sage. (Originally published 2009)

Sandlin, J. A., O'Malley, M. P., \& Burdick, J. (2011). Mapping the complexity of public pedagogy scholarship: 1894-2010. Review of Educational Research, 81(3), 338-375. https://doi.org/10.3102\%2F0034654311413395

Shotwell, A. (2016). Against purity: Living ethically in compromised times. Minneapolis, MN: Minnesota University Press.

Springgay, S., \& Truman, S. E. (2017a). On the need for methods beyond proceduralism: Speculative middles, (In) tensions, and reponse-ability in research. Qualitative Inquiry, 24(3), 203-214. https://doi.org/10.1177\%2F1077800417704464 
Springgay, S., \& Truman, S. E. (2017b). A transmaterial approach to walking methodologies: Embodiment, affect and a sonic art performance. Body \& Society, 23(4), 27-58. https://doi.org/10.1177\%2F1357034X17732626

Springgay, S., \& Truman, S. E. (2018). Walking Methodologies in a more-than-human world: WalkingLab. London, UK: Routledge.

Springgay, S., \& Truman, S. E. (2019a). Counterfuturisms and speculative temporalities: Walking Research-Creation in School. International Journal of Qualitative Studies in Education, 32(6), 547-559. https://doi.org/10.1080/09518398.2019.1597210

Springgay, S., \& Truman, S. E. (2019b). Queering temporalities, activating QTBIPOC subjectivities and world-makings: Walking research-creation. MAI: FEMINISM \& VISUAL CULTURE. Retrieved from https://maifeminism.com/walking-researchcreation-qtbipoc-temporalities-and-world-makings/

Springgay, S., \& Truman, S. E. (2019c). Research-creation walking methodologies and an unsettling of time. International Review of Qualitative Research, 12(1), 85-

93. https://doi.org/10.1525/irqr.2019.12.1.85

Stewart, K. (2007). Ordinary affect. Durham, NC: Duke University Press.

Styres, S. (2019). Literacies of land: Decolonizing narratives, storying, and literacies. In L. T. Smith, E. Tuck, \& K. W. Yang (Eds). Indigenous decolonizing studies in education (pp. 24-37). New York, NY: Routledge.

Sundberg, J. (2014). Decolonizing posthumanist geographies. Cultural Geographies, 21(1), 33-47. https://doi.org/10.1177\%2F1474474013486067

Tsing, A., Swanson, H., Gan, E., \& Bubandt, N. (Eds.) (2017). Arts of living on a damaged planet: Ghosts of the anthropocene. Minneapolis, MN: University of Minnesota Press.

Truman, S. E., \& Springgay, S. (2019). Queer Walking Tours and the affective contours of place. Cultural Geographies. Advance online publication. https://doi.org/10.1177\%2F1474474019842888

Tuck, E., \& McKenzie, M. (2015). Place in research. New York, NY: Routledge.

Yusoff, K. (2018). A billion black Anthropocenes or none. Minneapolis, MN: University of Minnesota Press.

Stephanie Springgay is an Associate Professor at the University of Toronto. She is a leading scholar of research-creation with a focus on walking, affect, queer theory, and contemporary art as pedagogy. She directs the SSHRC-funded research-creation project The Pedagogical Impulse which explores the intersections between contemporary art and pedagogy. With Dr. Sarah Truman she co-directs WalkingLab - an international network of artists and scholars committed to critical approaches to walking methods. Additionally, she is a stream lead on a SSHRC partnership grant Bodies in Translation: Activist Art, Technology, and Access to Life. Other curatorial projects include The Artist's Soup Kitchen - a 6 week performance project that explore food soveriegnty, queer feminist solidarity, and the communal act of cooking and eating together. She has published widely on contemporary art, curriculum studies, and qualitative research methodologies www.stephaniespringgay.com 
Sarah E. Truman is a Postdoctoral Research Fellow at the University of Melbourne where she researches English literary education, speculative fiction, and pedagogies of reading and writing. Her research is informed by the feminist new materialisms, theories of affect, and queer theory. Sarah is a researcher on the Teacher-Researchers Project (www.teacher-researchers.org); co-director of WalkingLab (www.walkinglab.org) and one-half of the electronic music duo Oblique Curiosities (www.obliquecuriosities.com). Her research-creation projects are detailed at www.sarahetruman.com.

\footnotetext{
${ }^{\mathrm{i}}$ Research-creation is the interrelated practices of art, theory, and research. While many arts-based approaches to qualitative research use the arts as a way of representing research findings, in research-creation the process of creative practice is understood as an empirical and theoretical practice itself
} 